\title{
Coping with branch excision when measuring leaf net photosynthetic rates in a lowland tropical forest
}

\author{
Verryckt Lore T. 1, * , Van Langenhove Leandro ${ }^{1}$, Ciais Philippe ${ }^{2}$, Courtois Elodie A. ${ }^{3}$, Vicca Sara ${ }^{1}$, \\ Peñuelas Josep ${ }^{4}$, Stahl Clément ${ }^{5}$, Coste Sabrina ${ }^{5}$, Ellsworth David S. ${ }^{6}$, Posada Juan M. ${ }^{7}$, \\ Obersteiner Michael ${ }^{8}$, Chave Jérôme ${ }^{9}$, Janssens Ivan A. ${ }^{1}$
}

1 Department of Biology University of Antwerp Wilrijk ,Belgium

2 Laboratoire des Sciences du Climat et de l'Environnement CEA-CNRS-UVSQ Gif-sur-Yvette ,France

${ }^{3}$ Laboratoire Ecologie, Évolution, Interactions des Systèmes Amazoniens (LEEISA) Université de Guyane CNRS IFREMER Cayenne, French Guiana

${ }^{4}$ CSIC Global Ecology CREAF-CEAB-CSIC-UAB Cerdanyola del Valles Barcelona, Spain

${ }^{5}$ UMR Ecofog, AgroParisTech, CNRS, Cirad INRA Université des Antilles Université de Guyane

Kourou ,France

${ }^{6}$ Hawkesbury Institute for the Environment Western Sydney University Penrith NSW ,Australia

7 Biology Department Faculty of Natural Sciences Universidad del Rosario Bogotá ,Colombia

8 International Institute for Applied Systems Analysis (IIASA) Laxenburg, Austria

9 UMR 5174 Laboratoire Evolution et Diversité Biologique Université Paul Sabatier CNRS

Toulouse ,France

*Corresponding author : Lore T. Verryckt, email address : lore.verryckt@uantwerpen.be

\begin{abstract}
:
Measuring leaf gas exchange from canopy leaves is fundamental for our understanding of photosynthesis and for a realistic representation of carbon uptake in vegetation models. Since canopy leaves are often difficult to reach, especially in tropical forests with emergent trees up to $60 \mathrm{~m}$ at remote places, canopy access techniques such as canopy cranes or towers have facilitated photosynthetic measurements. These structures are expensive and therefore not very common. As an alternative, branches are often cut to enable leaf gas exchange measurements. The effect of branch excision on leaf gas exchange rates should be minimized and quantified to evaluate possible bias. We compared light-saturated leaf net photosynthetic rates measured on excised and intact branches. We selected branches positioned at three canopy positions, estimated relative to the top of the canopy: upper sunlit foliage, middle canopy foliage, and lower canopy foliage. We studied the variation of the effects of branch excision and transport among branches at these different heights in the canopy. After excision and transport, light-saturated leaf net photosynthetic rates were close to zero for most leaves due to stomatal closure. However, when the branch had acclimated to its new environmental conditions-which took on average 20 min-lightsaturated leaf net photosynthetic rates did not significantly differ between the excised and intact branches. We therefore conclude that branch excision does not affect the measurement of light-saturated leaf net photosynthesis, provided that the branch is recut under water and is allowed sufficient time to acclimate to its new environmental conditions.
\end{abstract}


Keywords : branch cutting, canopy physiology, French Guiana, gas exchange, photosynthesis, rainforest, stomatal conductance 


\section{INTRODUCTION}

47 The measurement of leaf gas exchange is important for our understanding of photosynthesis (e.g. Dang, Margolis, Coyea, Sy \& Collatz, 1997, Schaberg, Shane, Cali, Donnelly \& Strimbeck,

49 1998, Domingues et al., 2010, Cavaleri, Reed, Smith \& Wood, 2015, Heberling, Kichey, Decocq \& Fridley, 2016), to understand processes of plant evolution and ecological strategies (Wright et al., 2004), and to improve the representation of carbon uptake in vegetation models (Rezende et al., 2016). In areas such as Amazonia, where the number of plants exceeds 14,000 about half being trees (Cardoso et al., 2017), the challenge of measuring leaf gas exchange across the region 54 is enormous. Even at accessible field sites, reaching canopy leaves is difficult, because they are 55 situated between 30 and $60 \mathrm{~m}$ above the ground (Perry, 1978).

Canopy cranes or towers have facilitated the in-situ measurement of leaf gas exchange in

57 forest canopies, but these structures are rare (Basset, Horlyck \& Wright, 2003, Nakamura et al., 58 2017). Therefore, branch excision is often necessary prior to leaf gas exchange measurement.

59 The excision of branches using a single-rope climbing technique (Perry, 1978), pole pruners, or 60 shotguns (e.g. Messier, Mcgill \& Lechowicz, 2010) are different methods that can give access to 61 leaves in the canopy. The effect of excision of branches on leaf gas exchange rates should 62 therefore be minimised and quantified to evaluate possible bias. Tropical studies measuring gas exchange on excised branches have reported different

64 effects of excision on the leaf net photosynthetic rate $\left(A_{\mathrm{n}}\right)$. Some species are not affected 65 (Santiago \& Mulkey, 2003, Rowland et al.,2015), whereas for other species $A_{\mathrm{n}}$ decreases within 66 a few minutes to several days (Santiago \& Mulkey, 2003). The reported effects can be caused by 67 alterations in the xylem stream after excision, influencing stomatal response (Sperry, Alder \& 68 Easttlack, 1993, Williamson \& Milburn, 1995). Therefore, it has been advised that prior to 
measurement, excised branches should be recut under water, to remove embolised xylem vessels

70 and to restore hydraulic conductivity for maintaining an adequate supply of water to the leaves.

71 Santiago and Mulkey (2003) and Rowland et al. (2015) studied upper-canopy, sunlit leaves.

72 However, several leaf physiological traits of tropical trees, such as $A_{s a t}$ and $g_{s}$, change with

73 height (Kenzo et al., 2015). The effect of excision might thus also vary with tree height. To the

74 best of our knowledge, vertical differences in the excision effect have not yet been investigated.

75 In this study, we therefore assessed whether the effect of excision varied with depth in the

76 canopy.

77 Measurement can be conducted at a nearby campsite (Rowland et al., 2015), or in a

78 laboratory further away (Ellsworth \& Reich, 1993, Dang et al.,1997), implying different timings

79 between excision and measurement and different environmental conditions. The excised

80 branches are thus treated in different ways prior to leaf gas exchange measurements, even though

81 the studies cited tried to minimise the time between excision and the actual measurement and to

82 maintain the original light conditions for the excised branch.

We assessed the effects of branch excision and transport on leaf net photosynthetic rate at

84 light saturation $\left(A_{\text {sat }}\right)$ and the variation of these effects amongst branches at different heights in

85 the canopy. We hypothesised that the effects of excision and transport would be smaller in the

86 canopy, because these branches are acclimated to darker conditions than the branches at the top

87 of the canopy. We assumed that they would be less stressed after excision and transport through

88 a dark forest. We therefore tested for a faster recovery of $A_{\text {sat }}$ for branches lower in the canopy.

\section{METHODS}

\subsection{Study site}


91 This study was conducted at the Nouragues Research Station ( $\left.4^{\circ} 02^{\prime} \mathrm{N}, 52^{\circ} 41^{\prime} \mathrm{W}\right)$, an old-

92 growth, tropical lowland forest site in French Guiana, South America. The climate is tropical

93 humid, with a dry season lasting from August to November and a short dry period in March.

94 Mean annual temperature is $26.3^{\circ} \mathrm{C}$ and mean annual rainfall is about $3000 \mathrm{~mm}$ (Bongers,

95 Charles-Dominique, Forget \& Théry, 2001).

\section{$96 \quad 2.2 \quad$ Measurement of leaf gas exchange}

97 We selected seven trees (Table 1) belonging to four dominant families at this field site:

98 Fabaceae, Lecythidaceae, Malvaceae, and Burseraceae. $A_{\text {sat }}\left(\right.$ measured at $\left.1300 \mu \mathrm{mol} / \mathrm{m}^{2} / \mathrm{s}\right)$ and

99 stomatal conductance $\left(\mathrm{g}_{\mathrm{s}} ; \mu \mathrm{mol} / \mathrm{m}^{2} / \mathrm{s}\right)$ were measured on mature leaves using an infrared gas

100 analyser (LI-6400XT, LI-COR, Lincoln, NE, USA). The measurements were carried out at three 101 canopy positions, estimated relative to the top of the canopy: upper sunlit foliage, middle canopy

102 foliage, and lower canopy foliage. We measured $A_{\text {sat }}$ at each position for at least three leaves on 103 an intact branch attached to the tree, with the assistance of a tree climber. This $2 \mathrm{~m}$-long branch 104 was subsequently excised, lowered gently from the canopy to a person who then immediately 105 recut the branch under water to reconstitute the water supply to the leaves, and transported 106 (within about ten minutes) to a nearby camp site in an opaque plastic bag to avoid further water 107 loss due to transpiration, where at least two leaves were measured on the excised branch. The 108 base of the branch always remained under water during transport. The branch was again recut 109 under water at the camp site to prevent from potential disruption of hydraulic conductivity that 110 may have arisen during transport. $A_{\mathrm{n}}$ at light saturation from these excised branches was

111 continuously logged. $A_{\mathrm{n}}$ was then defined as $A_{\text {sat }}$ when $A_{\mathrm{n}}$ remained stable, i.e. did not vary more 112 than five percent for at least two minutes. Relative humidity was maintained as near ambient as 113 possible (70-85\%), and the rate of air flow was $500 \mathrm{~mL} / \mathrm{min}$ during these measurements, which 
114 were carried out between $0930 \mathrm{~h}$ and $1500 \mathrm{~h}$. The $\mathrm{CO}_{2}$ level in the chamber was constant at 400

$115 \mathrm{ppm}$, and the chamber temperature was controlled by maintaining the block temperature at $30 \pm$ $116 \quad 0.2^{\circ} \mathrm{C}$.

117

118

119

120

121

122

123

124

125

126

127

128

129

130

131

132

133

134

135

We tested an additional tree species at the camp site, Eperua falcata, with sunlit leaves reachable from the ground without climbing. We tested the effect on $A_{\text {sat }}$ of transporting the excised branch in an opaque plastic bag. We continuously measured $A_{\mathrm{n}}$ at light saturation before excision and continued measuring it after excision without transporting the branch in a plastic bag. We also excised a branch, after measuring $A_{\text {sat, }}$, and transported it similarly to the other excised branches and again continuously measured $A_{\mathrm{n}}$ at light saturation to compare both methods. These measurements were carried out between $1000 \mathrm{~h}$ and $1130 \mathrm{~h}$.

\subsection{Data analyses}

The effect of excision on $A_{\text {sat }}$ was tested with a paired t-test, comparing pre- and post-cutting measurements for each leaf. We also tested if the slope of the linear regression between $A_{\text {sat }}$ for non-excised and excised branches differed from 1 . This analysis was carried out for all data, but also for upper, middle and lower canopy foliage separately. We analysed our $A_{\text {sat }}$ data using a two-way ANOVA, with excision (pre- or post-cutting), tree ID and canopy position (upper, middle, lower foliage) as fixed factors. We specifically explored the two-way interactions between these factors to assess the (interaction) effects of tree ID and canopy position on excision. We used $P<0.05$ to identify significant differences. Additionally we performed a bootstrap analysis (10,000 replicates) for this two-way ANOVA for which we allowed resampling within the same canopy position (upper, middle, lower foliage). We assumed that the interaction effects would not be significant if the bias-corrected and accelerated (BCa) 95\% 
136 confidence intervals included zero. All analyses were performed in R 3.3.3 (R Core Team, 2017)

137 using the ggplot2 package (Wickham, 2009) for visualising the data.

\section{RESULTS}

\subsection{Effect of excision}

140

141

142

143

144

145

146

147

148

149

150

151

152

153

154

155

156

In general, $A_{\text {sat }}$ did not differ significantly between the excised and non-excised branches (paired t-test: $P=0.10)$, and the slope of the linear regression did not differ significantly from $1(P=$ 0.21; Figure 1). When analysing the upper, middle and lower canopy foliage separately, the intercept and the slope of the linear regression did not differ significantly from $0\left(P_{\text {upper }}=0.79\right.$, $\left.P_{\text {middle }}=0.64, P_{\text {lower }}=0.54\right)$ and $1\left(P_{\text {upper }}=0.79, P_{\text {middle }}=0.86, P_{\text {lower }}=0.19\right)$, respectively. The two-way ANOVA showed no interaction between excision and tree $(P=0.59)$ or canopy position $(P=0.55)$. The interaction between tree ID and canopy position was significant $(P=$ 0.03), with different responses of $A_{\text {sat }}$ between tree IDs and canopy positions. Excision was not a significant factor in the two-way ANOVA $(P=0.49)$, indicating no differences in $A_{\text {sat }}$ before and after excision. Individual differences between pre- and post-cutting measurements of $A_{\text {sat }}$ are shown in Figure S1. The bootstrap analysis showed a tendency of an excision effect for tree 7, with BCa 95\% confidence intervals approaching zero [0.144, 4.317], whereas it did not show any effect for the other tree species, nor of canopy position, since these $\mathrm{BCa} 95 \%$ confidence intervals all included zero. Intrinsic water-use efficiency (iWUE) did not differ significantly between the excised and non-excised branches, with the slope of the linear regression not differing significantly from $1(P=0.66$; Figure $S 2)$.

\subsection{Effect of darkness in E. falcata: to bag or not to bag?}


157 Branch excision of the E. falcata tree in the camp had no effect on the continuously measured $A_{\mathrm{n}}$

158 at light saturation (Figure 2a). When the excised branch was first transported in a plastic bag and

$159 A_{\mathrm{n}}$ at light saturation was measured $10 \mathrm{~min}$ after recutting the branch under water, $A_{\mathrm{n}}$ at light

160 saturation was more than 50 percent lower than the original value (Figure $2 \mathrm{~b}$ ). $A_{\mathrm{n}}$ at light

161 saturation increased again after about 30 minutes of stabilisation, and $A_{\text {sat }}$ was similar to the

162 measurement on the intact branch in the tree.

\section{$163 \quad 3.3 \quad$ Stabilisation time}

$164 A_{\mathrm{n}}$ at light saturation after branch excision and transport to the camp was near zero $(<1$

$165 \mu \mathrm{mol} / \mathrm{m}^{2} / \mathrm{s}$ ) for 65 percent of the leaves and decreased by $30-80$ percent for the remainder of the

166 leaves. $A_{\mathrm{n}}$ increased over time after the leaf was placed in the leaf chamber and exposed to 1300

$167 \mu \mathrm{mol} / \mathrm{m}^{2} / \mathrm{s}$ photosynthetically active radiation (Figure $3 \mathrm{a}$ ), and $A_{\text {sat }} \operatorname{did}$ not differ significantly

168 from $A_{\text {sat }}$ for the leaf measured on the intact branch in the tree (Figure 1). The time to

169 stabilisation across all trees averaged $22 \mathrm{~min}$, but ranged between 6 and 44 min (Figure 3b,

170 Figure S3, Figure S4). The stabilisation time was longer for tree 7 than the other trees. The

171 stabilisation time was longer for upper canopy foliage (27 $\pm 9 \mathrm{~min})$ compared to middle (22 \pm 10

$172 \mathrm{~min}$ ) and lower (19 $\pm 7 \mathrm{~min})$ canopy foliage (Figure 3c).

\section{4. DISCUSSION}

174 We quantified the effects of branch excision on $A_{\text {sat }}$ as differences between $A_{\text {sat }}$ measured on an

175 intact branch in the tree and $A_{\text {sat }}$ measured on the same leaf after branch excision under water. $A_{\mathrm{n}}$

176 at light saturation decreased soon after the branch was excised and transported to the camp site

177 (Figure 2b, Figure S5a). This immediate decrease in $A_{\mathrm{n}}$ at light saturation was caused by stomatal

178 closure (Figure 2b, Figure S5b), but the stomata reopened on average 22 min after the branch 
was re-exposed to light (Figure $3 \mathrm{~b}, \mathrm{c}$ ). $A_{\mathrm{n}}$ at light saturation, however, did not decrease in the excised E. falcata branch kept in the light (Figure 2a), suggesting that the stomatal closure was due to light limitation rather than dehydration caused by excision. This requires confirmation by testing more tree species, because this was an unreplicated experiment. We only tested one species that we kept at constant light while excising the branch.

The cut branches were transported from the canopy to the forest floor, where less than two percent of the incoming light at the top of the canopy is typically available (Yoda, 1974, Théry, 2001, Montgomery \& Chazdon, 2002). We then cut the excised branch under water and transported it in an opaque bag to the camp site, where we measured leaf gas exchange. Light is a major determinant of stomatal conductance (Motzer, Munz, Küppers, Schmitt \& Anhuf, 2005), so both the dark conditions at the forest floor and the opaque bag likely induced stomatal closure. Stomata respond quickly to changing light conditions (Roelfsema \& Hedrich, 2005, Devireddy, Zandalinas, Gómez-Cadenas, Blumwald \& Mittler, 2018), allowing the plant to regulate its water-use efficiency. Stomata of the leaves can thus be expected to close after excision due to light limitation to maintain their water balance and to reopen when the leaves are re-exposed to light in the leaf chamber. The recovery of stomatal conductance and $A_{\mathrm{n}}$ was faster for leaves lower in the canopy and thus typically exposed to less light (Figure 3c), supporting our hypothesis that branches lower in the canopy would recover faster after excision. The differences in recovery time along a height gradient in the canopy might also be explained by the differences in leaf water potential. Upper-canopy leaves typically have a lower water potential and the branches at the top of the canopy might thus experience more stress when excised compared to middle- and lower-canopy branches (Koch, Sillett, Jennings \& Davis, 2004, Olson et al., 2018). 
201 Although we did not measure the leaf water potentials, our data on stomatal conductance and

202 intrinsic water use efficiency suggest that this did not play a major role in our study.

203

204

205

206

207

208

209

210

211

212

213

214

215

216

217

218

219

220

221

222

$A_{\text {sat }}$ did not differ significantly before and after excision at the camp site after acclimating to the new light conditions in the leaf chamber. The immediate decrease in $A_{\mathrm{n}}$ at light saturation was restored after, on average, $22 \mathrm{~min}$, which is in contrast to other studies where excision had no effect or a delayed decrease in $A_{\text {sat }}$ was shown (Lange, Führer \& Gebel, 1986, Meng \& Arp, 1992, Ellsworth \& Liu, 1994, Dang et al., 1997, Ambrose, Sillett \& Dawson, 2009, Dusenge et al., 2015, Rowland et al., 2015). Measurements of $A_{\text {sat }}$ on sugar maple leaves, immediately after excision and rehydration of the branch, were always within five percent of the rate measured on intact branches (Ellsworth \& Liu, 1994). Excision did not affect $A_{\text {sat }}$ in Pinus banksiana or Picea mariana, either immediately or during the next 14 h (Dang et al., 1997). Rowland et al. (2015) reported that excision did not affect photosynthesis in tropical trees. Our branches were allowed to stabilise in a canopy opening in full ambient irradiance for at least 30 min after recutting underwater prior to the measurements. Dusenge et al. (2015) found no difference in $V_{\mathrm{cmax}}$, the maximum carboxylation rate, and only a small negative effect on $J_{\max }$, the maximum electron transport rate, for tropical trees ten minutes before and after excision. $A_{\mathrm{n}}$ in twigs of Picea abies was constant for a minimum of 15 min after excision (Lange et al.,1986), and net photosynthesis of Picea rubens twigs did not vary significantly within about six minutes after detachment (Meng \& Arp, 1992). $A_{\text {sat }}$ did not decrease after excision in Sequoia sempervirens and $S$. giganteum in California, USA (Ambrose et al., 2009). The leaves for all these studies were exposed to full sunlight prior to measuring photosynthesis or were kept in the chamber under saturating light conditions, in contrast to our study. 
224 the photosynthetic rate for intact branches (i.e. pre-excision) $60 \mathrm{~min}$ after excision, whereas the

225 rates for other species were less than 40 percent of the rates for intact branches within three

226 minutes. The effect of excision can vary among species, and was shown to depend on the

227 production of latex or resin since these exudates might clog the xylem, reduce sap flow, and

228 thereby reduce foliar gas exchange (Santiago \& Mulkey, 2003). Excision did not generally affect

$229 A_{\text {sat }}$ in all seven of our species, although $A_{\text {sat }}$ decreased significantly after excision for sunlit

230 upper-canopy foliage for tree 2 (Tetragastris altissima) and middle-canopy foliage for trees 3

231 (Eschweilera coriacea) and 7 (E. falcata) (Figure S1). $A_{\text {sat }}$ may have decreased because the time

232 needed for the leaves to acclimate to the settings of light and humidity at the camp was not long

233 enough to reach $A_{\text {sat. For tree }} 2$ (Tetragastris altissima), belonging to the Burseraceae family that

234 is known to produce latex or resin (Plowden, Uhl \& De Assis Oliveira, 2004, Weeks, Daly \&

235 Simpson, 2005), the decrease in $A_{\text {sat }}$ after excision for sunlit, upper-canopy leaves might have

236 been influenced by the resin produced by this species, although we did not observe any resin

237 production. No decrease in $A_{\text {sat }}$ after excision was observed for middle and lower canopy leaves

238 of this tree. $A_{\text {sat }}$ measured in the camp on the excised branch was larger than $A_{\text {sat }}$ measured on the

239 intact branches for some trees (Figure S1), perhaps because xylem water potentials were higher

240 in the rehydrated excised branches than the intact branches (Comstock \& Ehleringer, 1984).

241 Since there was no significant decrease in $A_{s a t}$, we assume that there was no effect of excision on

242 leaf photosynthesis, although there is large variation among individually sampled leaves.

243 Additionally, given that we only sampled seven species, it is still recommended to test the effect

244 of excision before measuring leaf gas exchange for other species than those studied here or in 
245 previous studies (e.g. Santiago \& Mulkey, 2003, Ambrose et al., 2009, Dusenge et al., 2015,

246 Rowland et al., 2015).

247 We conclude that branch excision does not affect the measurement of $A_{\text {sat }}$ when the

248 branch is recut under water after excision and the measurement is carried out for a sufficiently

249 long time (at least 20 minutes) after the branch has acclimated to its new environmental

250 conditions for reopening the stomata. Light is necessary to reopen the stomata when the branch is

251 transported in dark conditions, either on the forest floor or inside an opaque bag. This process

252 could be facilitated by transporting the excised branch in a bag containing LED lights, or the

253 branch could be exposed to sunlight before measurement.

\section{ACKNOWLEDGEMENTS}

255 L. T. Verryckt is funded by a PhD fellowship from the Research Foundation Flanders (FWO). I.

256 A. Janssens acknowledges support from the European Research Council Synergy Grant; ERC-

257 2013-SyG-610028 IMBALANCE-P. We thank the staff of the Nouragues Natural Reserve and

258 The Nouragues Ecological Research Station, supported by USR mixte LEEISA (CNRS;

259 Cayenne, French Guiana). The research station has benefited from financial support by French

260 Investissement d'Avenir programs managed by the ANR (AnaEE-France ANR-11-INBS-0001;

261 Labex CEBA ANR-10-LABX-25-01).

262 We are grateful to Stefan van Beveren, Valentine Alt, Jean-Loup Touchard and Anthony

263 Percevaux for climbing the trees to collect the selected branches. We thank the rest of the team

264 for helping us with the field measurements. 


\section{CONFLICT OF INTEREST}

266 The corresponding author confirms on behalf of all authors that there have been no involvements

267 that might raise the question of bias in the work reported or in the conclusions, implications, or

268 opinions stated.

\section{DATA AVAILABILITY STATEMENT}

270 The data that support the findings of this study are openly available in Dryad Digital Repository

271 at https://doi.org/10.5061/dryad.v9s4mw6rg. 
272

273

274

275

276

277

278

279

280

281

282

283

284

285

286

287

288

289

290

291

292

293

294

\section{LITERATURE CITED}

Ambrose, A. R., Sillett, S. C., \& Dawson, T. E. (2009). Effects of tree height on branch hydraulics, leaf structure and gas exchange in California redwoods. Plant, Cell \& Environment, 32(7), 743-757. doi:10.1111/j.1365-3040.2009.01950.x

BASSET, Y., HoRlyck, V., \& Wright, S. J. (2003). Studying Forest Canopies from Above: The International Canopy Crane Network. Smithsonian Tropical Research Institute and UNEP.

Bongers, F., Charles-Dominique, P., Forget, P.-M., \& THERY, M. (2001). Nouragues: Dynamics and Plant-Animal Interactions in a Neotropical Rainforest. Kluwer Academic Publishers.

CARdoso, D., SÄrkinen, T., AleXander, S., Amorim, A. M., Bittrich, V., Celis, M., ... FORZZA, R. C. (2017). Amazon plant diversity revealed by a taxonomically verified species list. Proceedings of the National Academy of Sciences, 114(40), 10695-10700. doi:10.1073/pnas.1706756114

Cavaleri, M. A., Reed, S. C., SMith, W. K., \& Wood, T. E. (2015). Urgent need for warming experiments in tropical forests. Global Change Biology, 21, 2111-2121. doi: $10.1111 / \mathrm{gcb} .12860$

COMSTOCK, J., \& EHLERINGER, J. (1984). Photosynthetic responses to slowly decreasing leaf water potentials in Encelia frutescens. Oecologia, 61, 241-248. doi:10.1007/BF00396767

Dang, Q. L., Margolis, H. A., Coyea, M. R., Sy, M., \& CollatZ, G. J. (1997). Regulation of branch-level gas exchange of boreal trees: roles of shoot water potential and vapor pressure difference. Tree Physiology, 17(8-9), 521-535. doi:10.1093/treephys/17.8-9.521 
Devireddy, A. R., Zandalinas, S. I., GómeZ-Cadenas, A., Blumwald, E., \& Mittler, R. (2018). Coordinating the overall stomatal response of plants: Rapid leaf-to-leaf communication during light stress. Science Signaling, 11(518), eaam9514. doi:10.1126/scisignal.aam9514

Domingues, T. F., Meir, P., FeldPausch, T. R., SAiz, G., VeenendaAl, E. M., Schrodt, F., ... LLOYD, J. (2010). Co-limitation of photosynthetic capacity by nitrogen and phosphorus in West Africa woodlands. Plant, Cell \& Environment, 33, 959-980. doi:10.1111/j.13653040.2010.02119.x

Dusenge, M. E., Walling, G., GÅrdesten, J., Nyronzima, F., Adolfsson, L., Nsabimana, D., \& UdDLING, J. (2015). Photosynthetic capacity of tropical montane tree species in relation to leaf nutrients, successional strategy and growth temperature. Oecologia, 117, 1183-1194. doi:10.1007/s00442-015-3260-3

ELLSWORTH, D. S., \& LIU, X. (1994). Photosynthesis and canopy nutrition of four sugar maple forests on acid soils in northern Vermont. Canadian Journal of Forest Research, 24, 2118-2127. doi:10.1139/x94-272

Ellsworth, D. S., \& REICH, P. B. (1993). Canopy structure and vertical patterns of photosynthesis and related leaf traits in a deciduous forest. Oecologia, 96, 169-178. doi:10.1007/BF00317729

Heberling, J. M., Kichey, T., DecocQ, G., \& Fridley, J. D. (2016). Plant functional shifts in the invaded range: a test with reciprocal forest invaders of Europe and North America. Functional Ecology, 30(6), 875-884. doi:10.1111/1365-2435.12590 
KENZO, T., INOUE, Y., YOSHIMURA, M., YAMASHITA, M., TANAKA-ODA, A., \& ICHIE, T. (2015). Height-related changes in leaf photosynthetic traits in diverse Bornean tropical rain forest trees. Oecologia, 177, 191-202. doi:10.1007/s00442-014-3126-0

KOCH, G. W., SILLETT, S. C., JENNINGS, G. M., \& DAVIS, S. D. (2004). The limits to tree height. Nature, 428, 851-854. doi:10.1038/nature02417

LANGE, O. L., FÜHRER, G., \& GEBEL, J. (1986). Rapid field determination of photosynthetic capacity of cut spruce twigs (Picea abies) at saturating ambient CO2. Trees, 1, 70-77. doi:10.1007/bf00197027

MENG, F.-R., \& ARP, P. A. (1992). Net photosynthesis and stomatal conductance of red spruce twigs before and after twig detachment. Canadian Journal of Forest Research, 23, 716721. doi:10.1139/x93-093

Messier, J., McGill, B. J., \& LeCHOwicz, M. J. (2010). How do traits vary across ecological scales? A case for trait-based ecology. Ecology Letters, 13(7), 838-848. doi:10.1111/j.1461-0248.2010.01476.x

MONTGOMERY, R., \& CHAZDON, R. (2002). Light gradient partitioning by tropical tree seedlings in the absence of canopy gaps. Oecologia, 131(2), 165-174. doi:10.1007/s00442-002$0872-1$

MotZer, T., MunZ, N., KÜPPERS, M., SCHMitT, D., \& ANHUF, D. (2005). Stomatal conductance, transpiration and sap flow of tropical montane rain forest trees in the southern Ecuadorian Andes. Tree Physiology, 25, 1283-1293. doi:10.1093/treephys/25.10.1283

Nakamura, A., Kitching, R. L., CaO, M., Creedy, T. J., Fayle, T. M., Freiberg, M., ... Ashton, L. A. (2017). Forests and Their Canopies: Achievements and Horizons in 
Canopy Science. Trends in Ecology \& Evolution, 32(6), 438-451. doi:10.1016/j.tree.2017.02.020

OLSON, M. E., SORIANO, D., ROSELL, J. A., ANFODILLO, T., DONOGHUE, M. J., EDWARDS, E. J., ... MÉNDEZ-ALONZO, R. (2018). Plant height and hydraulic vulnerability to drought and cold. PNAS, 115(29), 7551-7556.

doi:10.1073/pnas.1721728115

PERRY, D. R. 1978. A method of access into the crowns of emergent and canopy trees. Biotropica, 10(2), 155-157. doi:10.2307/2388019

PLOWDEN, C., UHL, C., \& DE ASSIS OLIVEIRA, F. (2004). Alipumilio (Diptera: Syrphidae) fly association with Burseraceae tree resins in the eastern Brazilian Amazon. Journal of Natural History, 38(15), 1941-1947. doi:10.1080/00222930310001618886

R CORE TEAM. 2017. R: A Language and Environment for Statistical Computing. R Foundation for Statistical Computing, Vienna, Austria.

Rezende, L. F. C., Arenque, B. C., Aidar, S. T., Moura, M. S. B., Von Randow, C., TOURIGNY, E., ... OMETTO, J. P. H. B. (2016). Evolution and challenges of dynamic global vegetation models for some aspects of plant physiology and elevated atmospheric CO2. International Journal of Biometeorology, 60(7), 945-955. doi:10.1007/s00484-015$1087-6$

RoElfSEMA, M. R., \& HEDRICH, R.. 2005. In the light of stomatal opening: new insights into 'the Watergate'. New Phytologist, 167, 665-691. doi:10.1111/j.1469-8137.2005.01460.x

Rowland, L., Lobo-do-Vale, R. L., Christoffersen, B. O., Melem, E. A., Kruijt, B., VASCONCELOS, S. S., ... MEIR, P. (2015). After more than a decade of soil moisture 
deficit, tropical rainforest trees maintain photosynthetic capacity, despite increased leaf respiration. Global Change Biology, 21(12), 4662-4672. doi:10.1111/gcb.13035

Santiago, L. S., \& MulKey, S. S. (2003). A test of gas exchange measurements on excised canopy branches of ten tropical tree species. Photosynthetica, 41(3), 343-347. doi:10.1023/B:PHOT.0000015457.92479.eb

Schaberg, P. G., Shane, J. B., Cali, P. F., Donnelly, J. R., \& Strimbeck, G. R. (1998). Photosynthetic capacity of red spruce during winter. Tree Physiology, 18, 271-276.

SPERRY, J. S., AldER, N. N., \& EASTLACK, S. E. (1993). The Effect of Reduced Hydraulic Conductance on Stomatal Conductance and Xylem Cavitation. Journal of Experimental Botany, 44(6), 1075-1082. doi:10.1093/jxb/44.6.1075

ThE PlanT List. 2013. Version 1.1. http://www.theplantlist.org/ (accessed November 2018).

THÉRY, M. (2001) Forest light and its influence on habitat selection. Plant Ecology, 153(1-2), 251-261. doi:10.1023/A:1017592631542

VERRYCKT, L. T., VAN LANGENHOVE, L., CIAIS, P., COURTOIS, E. A., VICCA, S., PEÑUELAS, J., ... JANSSENS, I. A. (2020). Data from: Coping with branch excision when measuring leaf net photosynthetic rates in a lowland tropical forest. Dryad Digital Repository. doi:10.5061/dryad.v9s4mw6rg

WEEKS, A., DALY, D. C., \& SIMPSON, B. B. (2005). The phylogenetic history and biogeography of the frankincense and myrrh family (Burseraceae) based on nuclear and chloroplast sequence data. Molecular Phylogenetics and Evolution, 35, 85-101. doi:10.1016/j.ympev.2004.12.021

WICKHAM, H. (2009). ggplot2: Elegant Graphics for Data Analysis. . Springer-Verlag New York. 
383 Williamson, V. G., \& Milburn, J. A. (1995). Cavitation events in cut stems kept in water:

384 implications for cut flower senescence. Scientia Horticulturae, 64(4), 219-232.

385 doi:10.1016/0304-4238(95)00842-X

386 Wright, I. J., Reich, P. B., Westoby, M., Ackerly, D. D., BARuch, Z., Bongers, F., ...

387 VILLAR, R. (2004). The worldwide leaf economics spectrum. Nature, 428(6985), 821-

$388 \quad$ 827. doi:10.1038/nature02403

389 YoDA, K. (1974). Three-dimensional distribution of light intensity in a tropical rain forest of

390 West Malaysia. Japanese Journal of Ecology, 24(4), 247-254.

391

doi:10.18960/seitai.24.4_247

392 
394 Table 1. Overview of the tree species selected for this study. The Plant List (2013) was used to validate the scientific 395 names and to confirm authorship. The diameter at breast height (DBH) and total height are given for each tree. The 396 heights of the upper, middle, and lower canopy foliage indicate the heights above the ground surface at which the 397 branches were sampled.

\begin{tabular}{|c|c|c|c|c|c|c|c|}
\hline $\begin{array}{l}\text { Tree } \\
\text { ID }\end{array}$ & Family & Species name & $\begin{array}{l}\text { DBH } \\
(\mathrm{cm})\end{array}$ & $\begin{array}{l}\text { Total } \\
\text { height }(\mathbf{m})\end{array}$ & $\begin{array}{l}\text { Height } \\
\text { upper } \\
\text { foliage (m) }\end{array}$ & $\begin{array}{l}\text { Height middle } \\
\text { foliage }(\mathbf{m})\end{array}$ & $\begin{array}{l}\text { Height } \\
\text { lower } \\
\text { foliage (m) }\end{array}$ \\
\hline 1 & Malvaceae & $\begin{array}{l}\text { Sterculia cf. } \\
\text { multiovula E.L. } \\
\text { Taylor }\end{array}$ & 39.5 & 32 & 30 & 25 & 20 \\
\hline 2 & Burseraceae & $\begin{array}{l}\text { Tetragastris altissima } \\
\text { (Aubl.) Swart }\end{array}$ & 47.4 & 30 & 27 & 23 & 20 \\
\hline 3 & $\begin{array}{l}\text { Lecythidacea } \\
\mathrm{e}\end{array}$ & $\begin{array}{l}\text { Eschweilera coriacea } \\
\text { (DC.) S.A. Mori }\end{array}$ & 53.2 & 38 & 36 & 32 & 25 \\
\hline 4 & $\begin{array}{l}\text { Lecythidacea } \\
\mathrm{e}\end{array}$ & $\begin{array}{l}\text { Lecythis persistens } \\
\text { Sagot }\end{array}$ & 47.4 & 42 & 42 & 34 & 29.5 \\
\hline 5 & $\begin{array}{l}\text { Lecythidacea } \\
\mathrm{e}\end{array}$ & $\begin{array}{l}\text { Eschweilera coriacea } \\
\text { (DC.) SA. Mori }\end{array}$ & 54.7 & 35 & 33 & 29 & 23 \\
\hline 6 & Fabaceae & Inga sp. & 36.6 & 31 & 28 & 22 & 17.5 \\
\hline 7 & Fabaceae & Eperua falcata Aubl. & 81.8 & 40 & 38 & 33 & 27 \\
\hline
\end{tabular}


399 FIGURE 1 Leaf net photosynthetic rate at light saturation $\left(A_{\text {sat }} ; \mu \mathrm{mol} / \mathrm{m}^{2} / \mathrm{s}\right)$ for non-excised

400 (intact $\left.A_{\text {sat }}\right)$ and excised (excised $\left.A_{\text {sat }}\right)$ branches $(\mathrm{n}=21)$. Each point represents an average of 2-3

401 leaves for each canopy position and tree, with standard errors on the $\mathrm{x}$ - and y-axes. The slope of 402 the linear regression did not differ significantly from $1(P=0.63)$. The black line represents the

403 1:1 line and the grey shading shows the $95 \%$ confidence interval.

404 FIGURE 2 Leaf net photosynthetic rate $\left(A_{\mathrm{n}} ; \mu \mathrm{mol} / \mathrm{m}^{2} / \mathrm{s}\right)$ at light saturation and stomatal

405 conductance $\left(g_{s} ; \mu \mathrm{mol} / \mathrm{m}^{2} / \mathrm{s}\right)$ in Eperua falcata as functions of time of day, during an

406 unreplicated experiment to test the effect of transporting the excised branch in an opaque plastic

407 bag on $A_{\text {sat }}$ (A) $A_{\mathrm{n}}$ was continuously measured before and after excision of the branch. The solid

408 black line represents the time of excision. (B) $A_{\mathrm{n}}$ was measured on the attached branch. The

409 excised branch was transported in an opaque plastic bag, and $A_{\mathrm{n}}$ was again continuously

410 measured after 10 min until $A_{\mathrm{n}}$ had stabilised and differed by less than five percent from the

411 original values before excision. The dashed line represents $A_{\mathrm{n}}$ before excision.

412 FIGURE 3 (A) Actual data of a representative response of continuously measured leaf net

413 photosynthetic rate $\left(A_{\mathrm{n}}\right)$ at light saturation after excision and transport of the branch. Time 0

414 corresponds to the placement of the leaf in the gas exchange chamber. (B) Average stabilisation

415 time for the seven trees. The error bars are the standard errors of the mean. No data are available

416 for tree 5, because we $\operatorname{did}$ not $\log A_{\mathrm{n}}$ continuously. (C) Average stabilisation time for branches at 417 different positions in the canopy (U, upper; M, middle; L, lower) for the seven trees. The error 418 bars are the standard errors of the mean. 
Figure 1

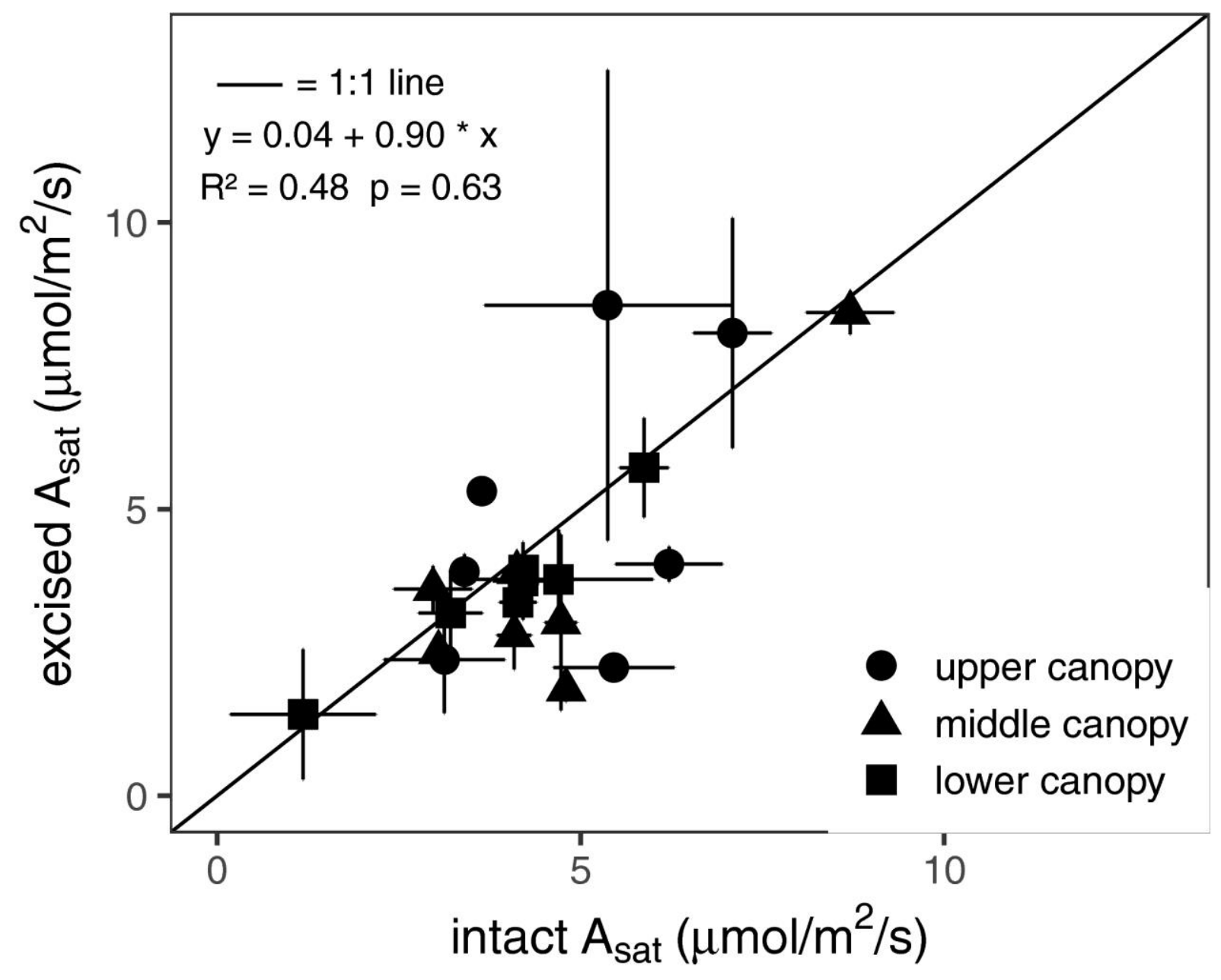


Figure 2

(a)

- $A_{n} \Delta g_{s}$
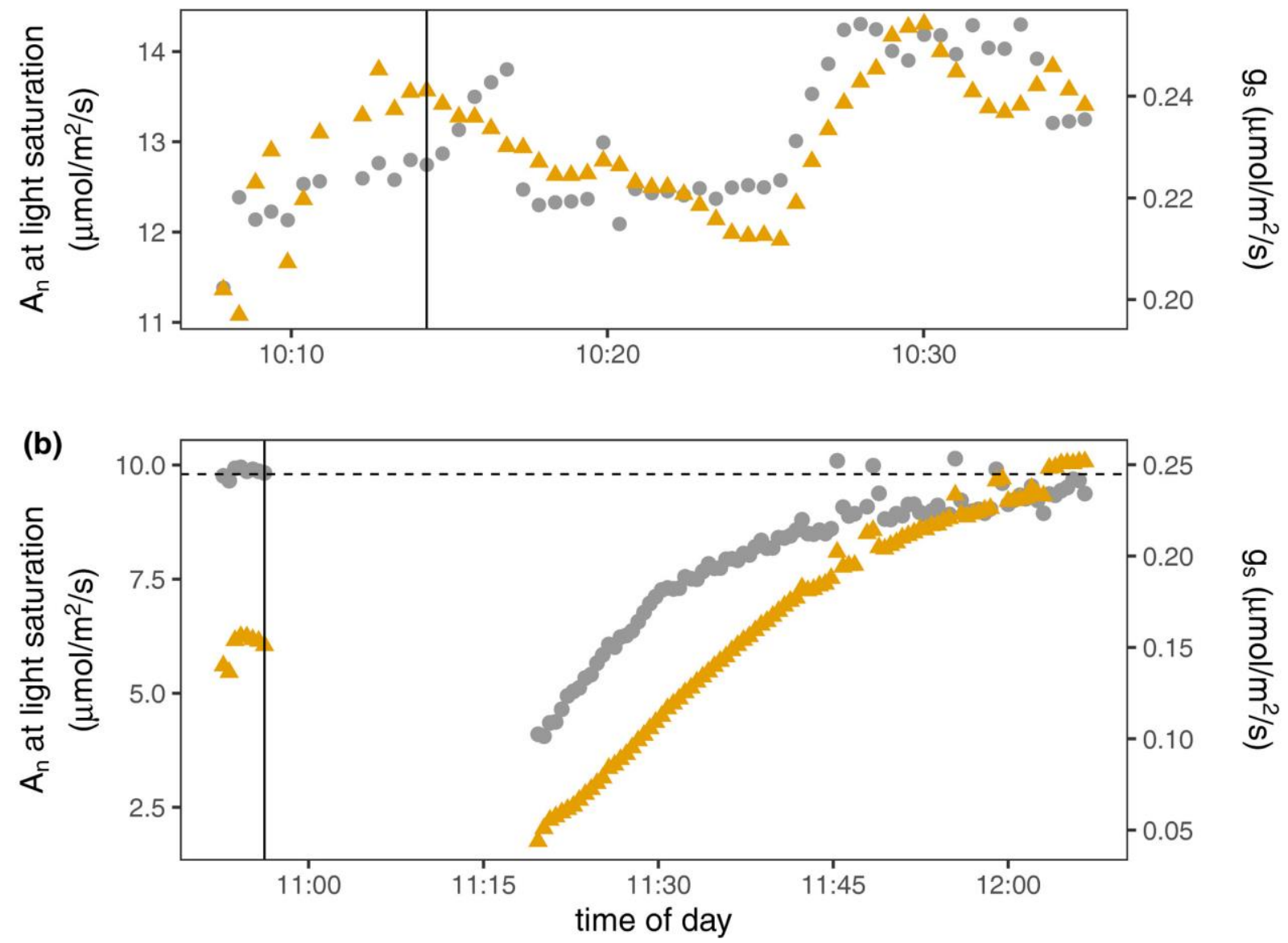
Figure 3
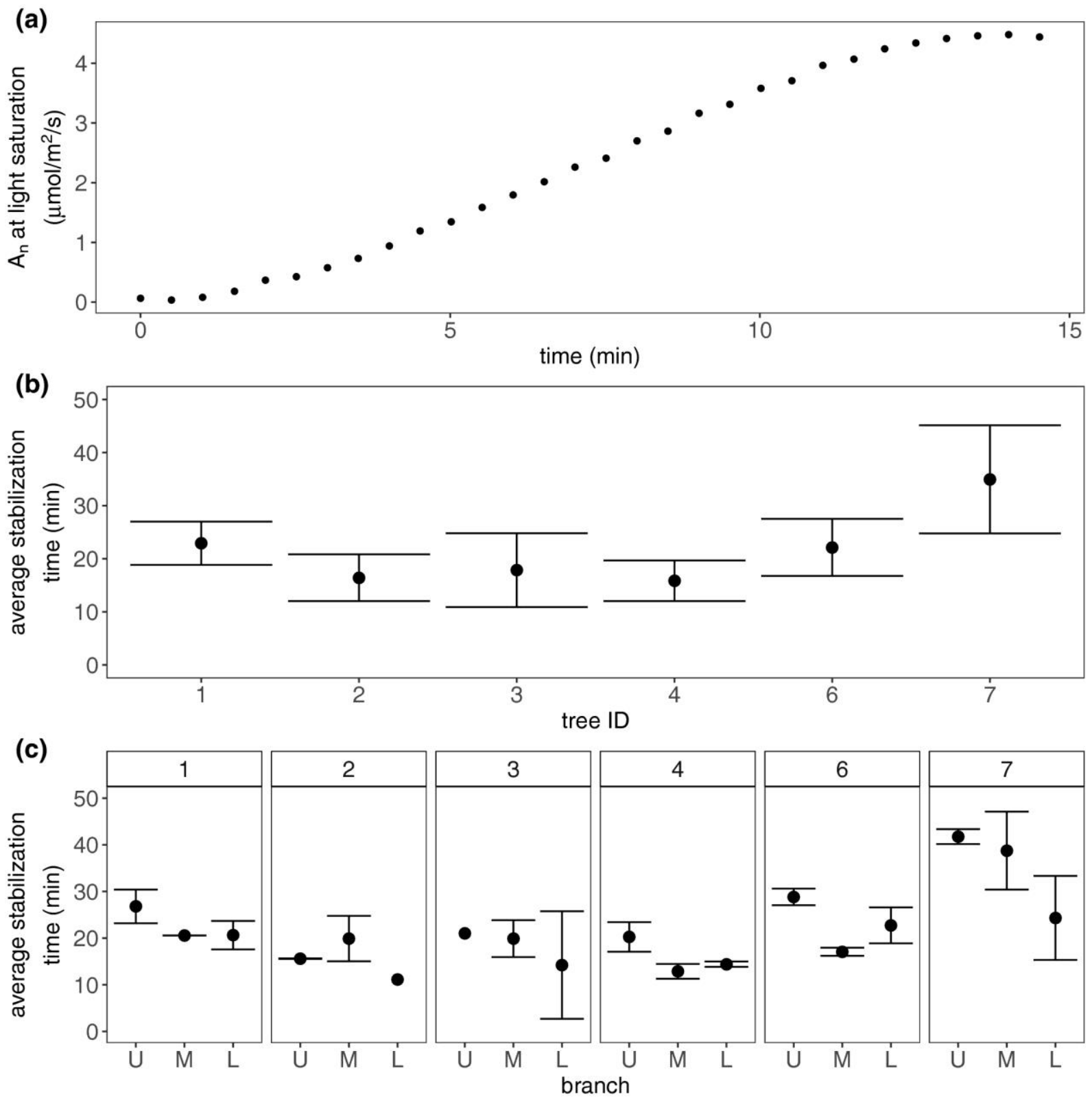


\section{SUPPORTING INFORMATION}

Article title: Coping with branch excision when measuring leaf net photosynthetic rates in a lowland tropical forest

Authors: Lore T. Verryckt ${ }^{1}$, Leandro Van Langenhove ${ }^{1}$, Philippe Ciais ${ }^{2}$, Elodie A. Courtois ${ }^{3}$, Sara Vicca ${ }^{1}$, Josep Peñuelas ${ }^{4}$, Clément Stahl ${ }^{5}$, Sabrina Coste $^{6}$, David S. Ellsworth ${ }^{7}$, Juan M. Posada $^{8}$, Michael Obersteiner ${ }^{9}$, Jérôme Chave ${ }^{10}$, Ivan A. Janssens ${ }^{1}$

The following Supporting Information is available for this article:

FIGURE S1 Box and whisker plots of the replicates of leaf net photosynthetic rate at light saturation $\left(A_{\text {sat }} ; \mu \mathrm{mol} \mathrm{m} \mathrm{m}^{-2} \mathrm{~s}^{-1}\right)$ compared between attached (tree) and excised (camp) branches for (a) upper sunlit foliage, (b) middle canopy foliage, and (c) lower canopy foliage.

FIGURE S2 Intrinsic water-use efficiency (iWUE; $\mu$ mol CO${ }_{2}$ mol $^{-1} \mathrm{H}_{2} \mathrm{O}$ ) compared between non-excised (tree iWUE) and excised (camp iWUE) branches $(\mathrm{n}=21)$.

FIGURE S3 Actual data of continuously measured leaf net photosynthetic rate $\left(A_{n}\right)$ at light saturation after excision and transport of the branch.

FIGURE S4 Histogram of the stabilisation times (min) for six trees.

FIGURE S5 Leaf net photosynthetic rate $\left(A_{n}\right)$ at light saturation and stomatal conductance $\left(g_{s}\right)$ compared between the start of the continuously logged leaf gas exchange measurements (time 0 ) and when $\mathrm{A}_{\mathrm{n}}$ remained stable. 

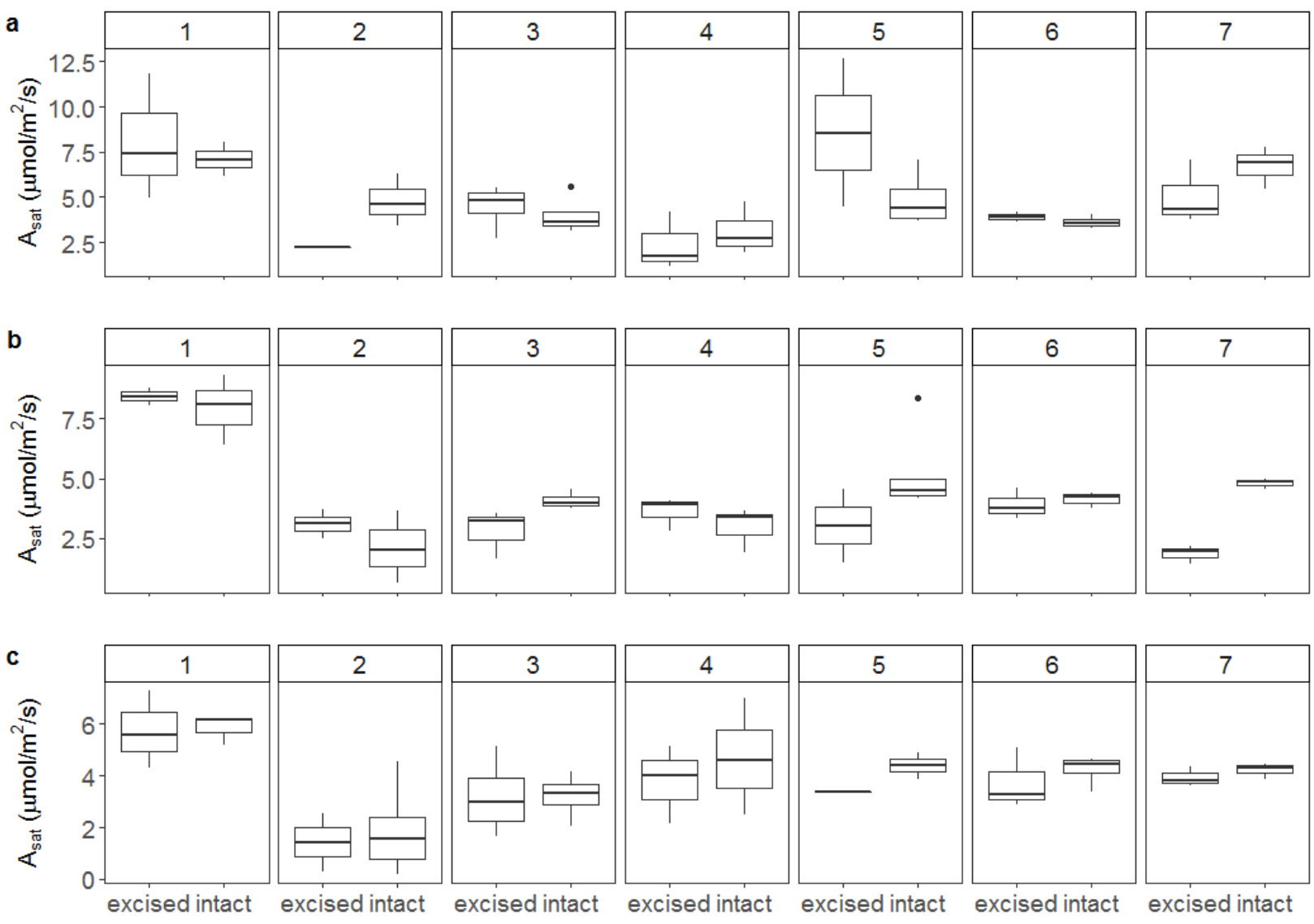

Fig. S1 Box and whisker plots of the replicates of leaf net photosynthetic rate at light saturation $\left(A_{\text {sat }} ; \mu \mathrm{mol} / \mathrm{m}^{2} / \mathrm{s}\right)$ compared between attached (intact) and excised (excised) branches for (A) upper sunlit foliage, (B) middle canopy foliage, and $(C)$ lower canopy foliage. A two-way ANOVA showed no interaction between excision and tree $(P=0.59)$ or canopy position $(P=0.55)$. The numbers above the plots are the tree IDs (see Table 1). The height of the box is the interquartile range, the horizontal bar is the median, the whiskers extend to 1.5 times the first or third quartile, the circles are outliers. 


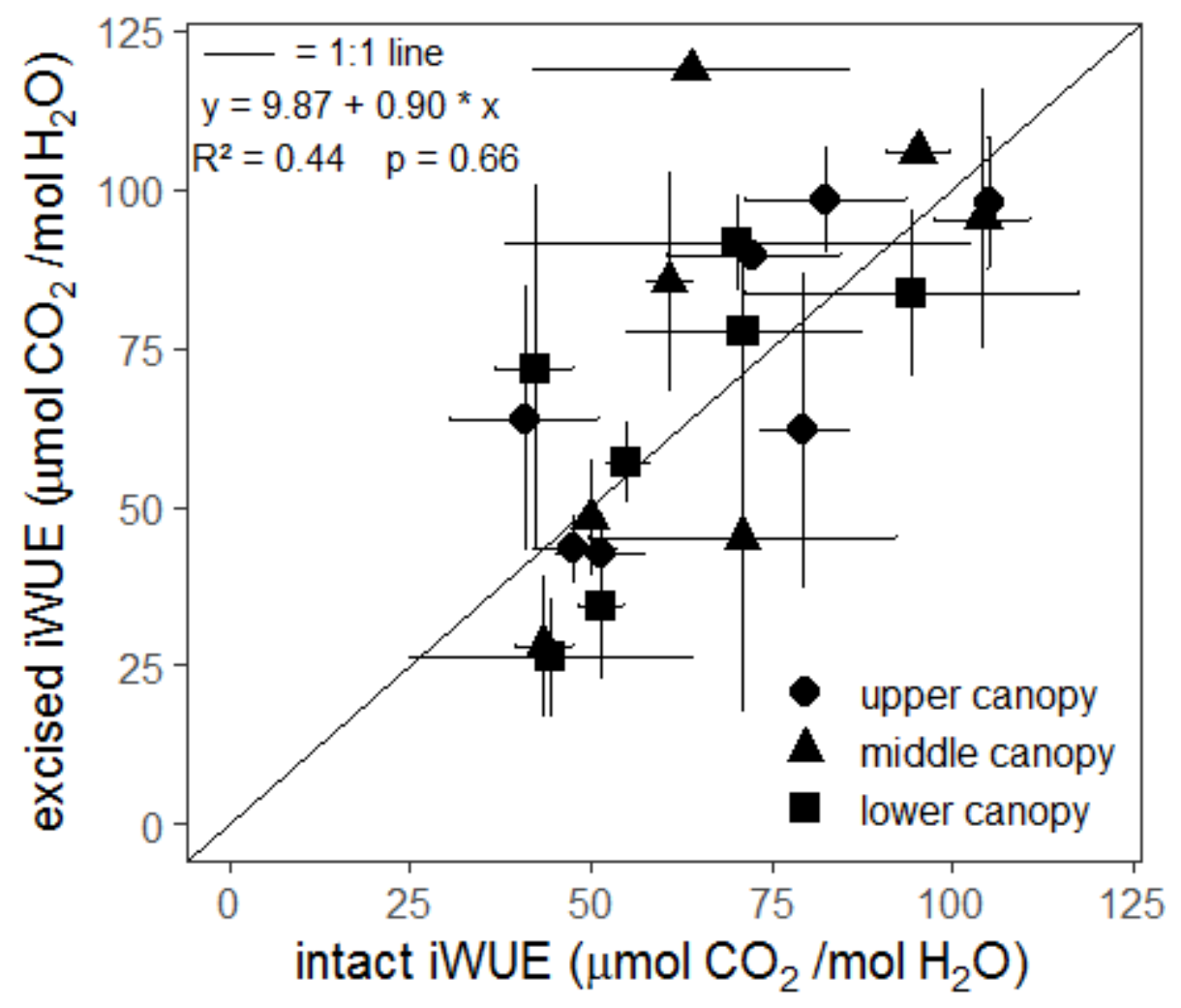

Fig. S2 Intrinsic water-use efficiency (iWUE; $\mu$ mol $\left.\mathrm{CO}_{2} / \mathrm{mol} \mathrm{H}_{2} \mathrm{O}\right)$ compared between non-excised (intact $i W U E)$ and excised (excised $i W U E)$ branches $(n=21)$. iWUE was calculated as leaf net photosynthetic rate at light saturation $\left(A_{\text {sat }}\right)$ divided by stomatal conductance measured at $A_{\text {sat. }}$ Each point represents an average of 2-3 leaves for each canopy position for each tree, with standard errors on the $x$ - and y-axes. The circles, triangles, and squares represent upper, middle, and lower canopy branches, respectively. The branches were cut (y-axis), so iWUE for the excised branches may not be identical to iWUE for intact branches. Excision, however, did not significantly affect $i W U E$; the slope of the linear regression did not differ significantly from 1 ( $P$ =0.66). The black line represents the 1:1 line. 

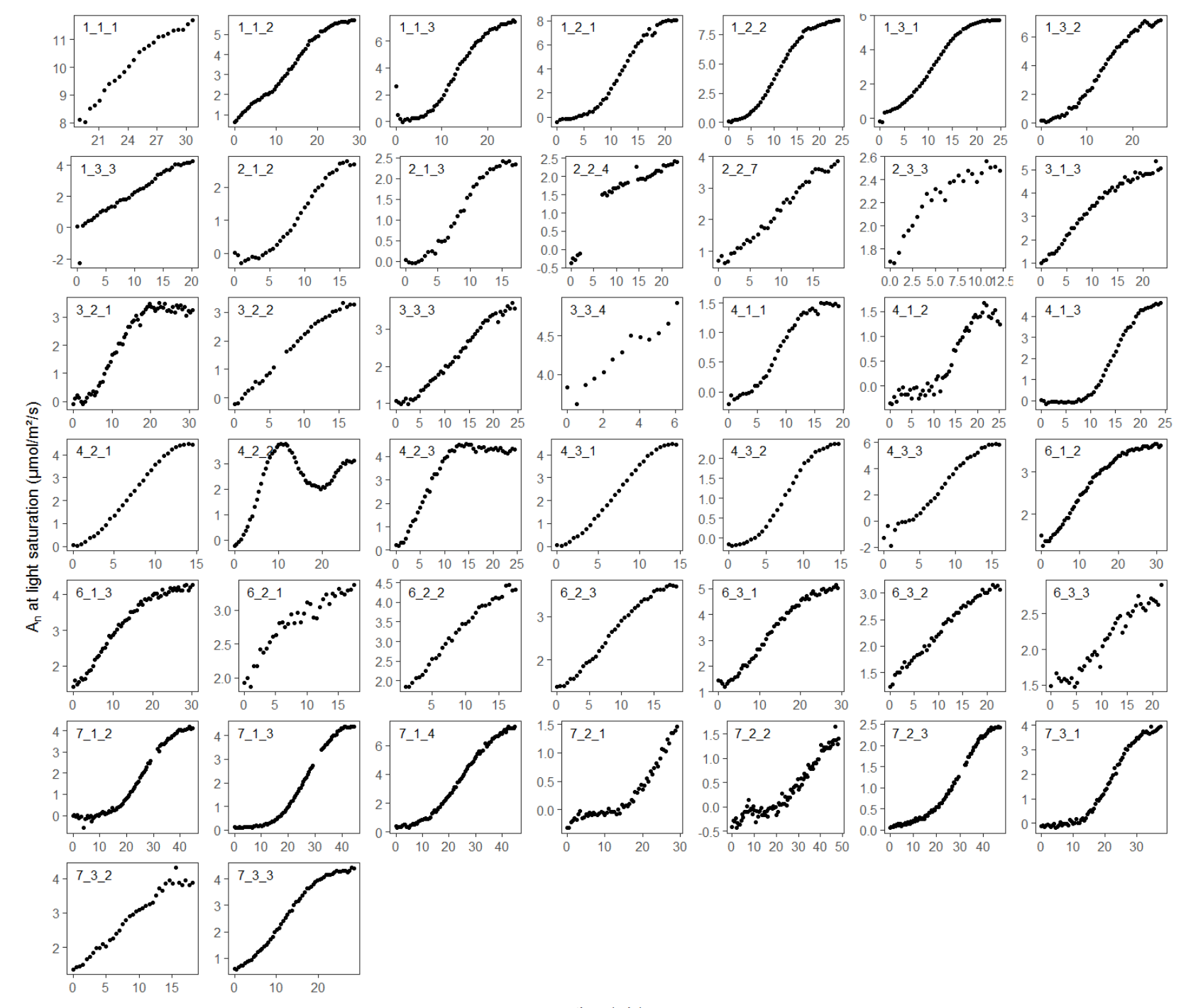

time (min)

Fig. S3 Actual data of continuously measured leaf net photosynthetic rate $\left(A_{n} ; \mu \mathrm{mol} / \mathrm{m}^{2} / \mathrm{s}\right)$ at light saturation after excision and transport of the branch. Time 0 corresponds to the placement of the leaf in the gas exchange chamber. The ID number of each plot refers to the tree number (1-7; no data available for tree 5 since we did not $\log A_{n}$ continuously), followed by the canopy height (1 = upper canopy, 2 = middle canopy, 3 = lower canopy) and the number of the replicate. 


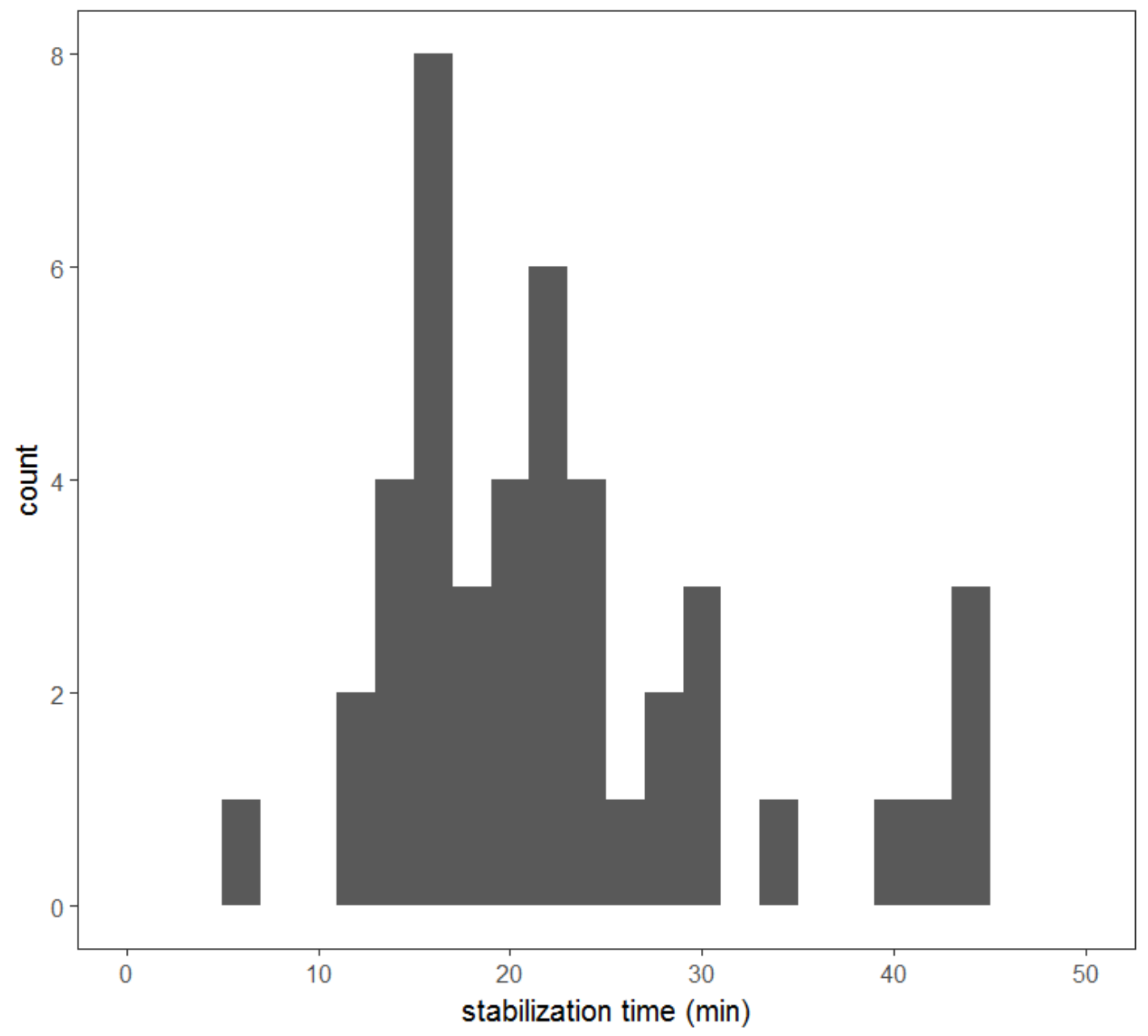

Fig. S4 Histogram of the stabilization times ( $\mathrm{min}$ ) for six trees. No data are available for tree 5, because we did not $\log A_{n}$ continuously. 

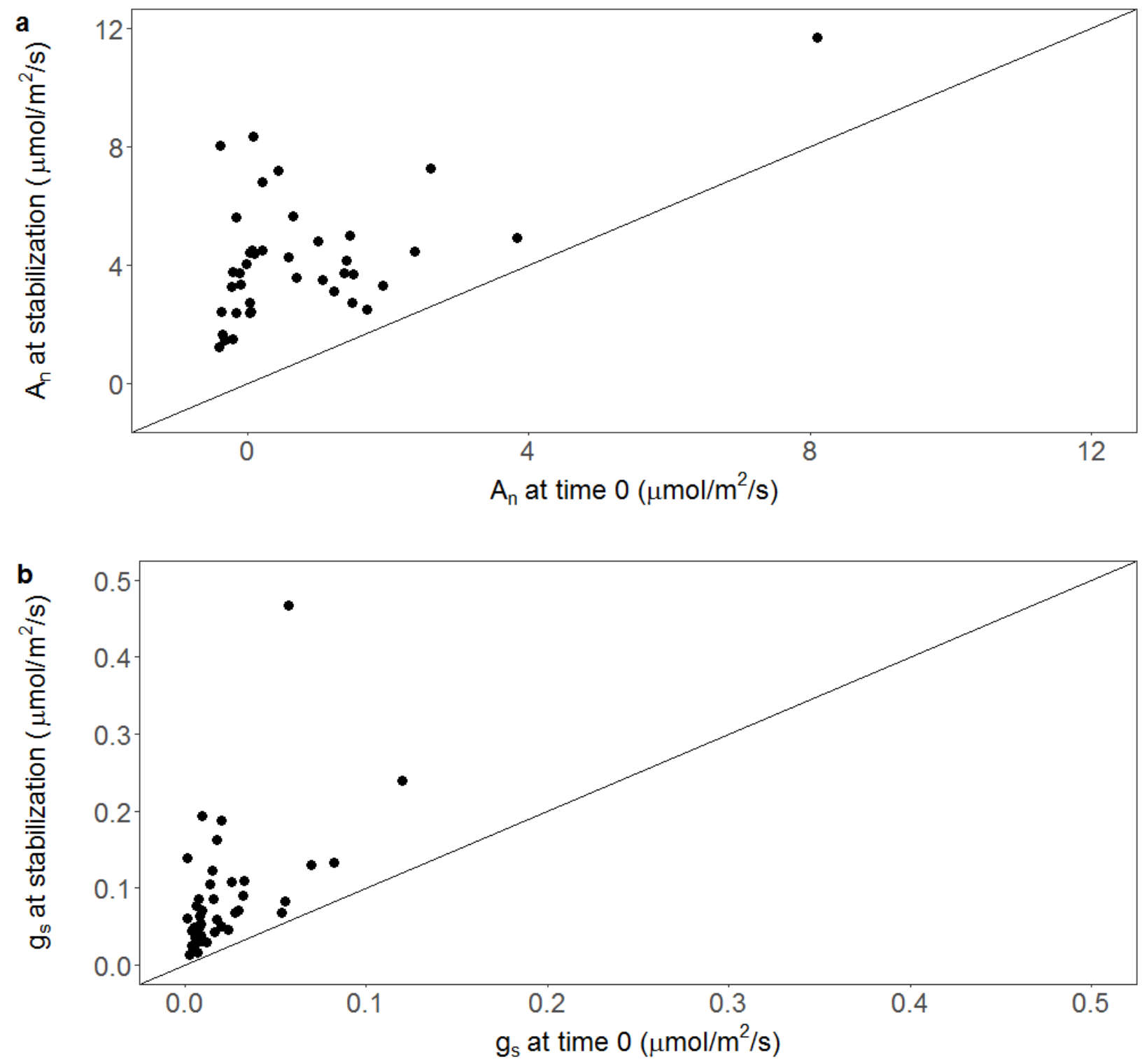

Fig. S5 (A) Leaf net photosynthetic rate $\left(A_{n}\right)$ at light saturation and $(B)$ stomatal conductance $\left(g_{s}\right)$ measured at the start of the continuously logged leaf gas exchange measurements (time 0) and when $A_{n}$ remained stable (at stabilisation, i.e. $A_{n}$ did not vary by more than five percent for at least two minutes). 